\title{
A Conversation with $\mathrm{Mu}-\mathrm{Fa}$ Chen
}

\author{
Davar Khoshnevisan and Edward Waymire
}

Mu-Fa Chen is among China's most distinguished and influential living resident probabilists. He and his student F. K. Wang found sharp estimates for the eigenvalues of the Laplacian on a manifold in terms of the Ricci curvature and diameter by probabilistic methods, as explained in his 2005 Springer monograph Eigenvalues, Inequalities, and Ergodic Theory. Having spent his entire career in China, Professor Chen's invited address at the May 16, 2016 Frontier Probability Days Conference, held at the University of Utah, presented a welcome opportunity to interview him.

Mu-Fa Chen: I grew up in the countryside, in a very small village of about eighty people in southern China. I had not seen a train and never rode a bus; we only rode bicycles.

Khoshnevisan/Waymire: What do you remember about your school?

Mu-Fa Chen: I was especially lucky because, during my time, two very good teachers-one from Shaman University and the other from Tsinghua Universitymoved to my middle school.

In the beginning, I studied mathematics by myself.

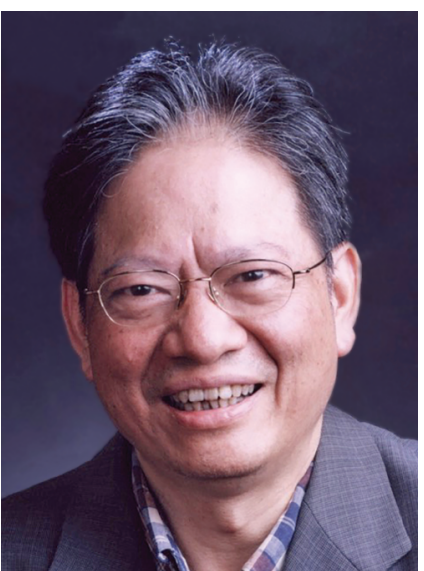

Mu-Fa Chen, official portrait as a member of Beijing. Academy of Science, 2006,

I wanted to create something. I did not know how to learn mathematics, so I just looked for exercises. I did exercises everyday.

Khoshnevisan/Waymire: At what age was this?

Mu-Fa Chen: At fourteen, I think. Then I read some popular little books written by famous Chinese mathematicians. I spent about one or two years reading these small books. Then one day the teacher who came from Tsinghua University told me, "No, no, you cannot just read

Davar Khoshnevisan is professor of mathematics at University of Utah. His e-mail address is davarkhoshnevi san@gmai 1 . com.

Edward Waymire is professor of mathematics at Oregon State University. His e-mail address is waymi re@math . oregonstate. edu.

For permission to reprint this article, please contact:

reprint-permission@ams . org.

DOI: http://dx.doi.org/10.1090/noti1533

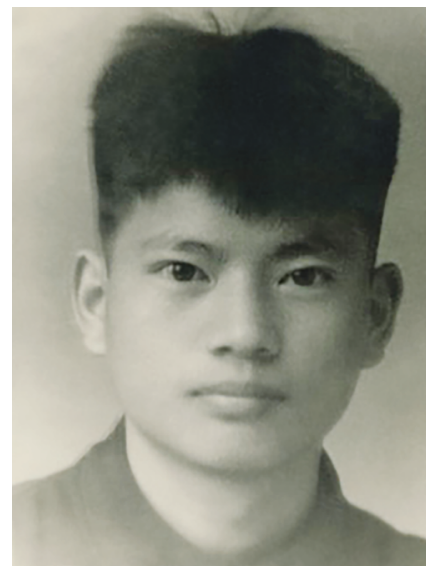

Chen graduated from high school in 1965. these things. You should study calculus." So, I started to learn calculus by myself. I spent two or more years studying calculus and algebra in middle school. So I am lucky because of my teachers.

Khoshnevisan/Way mire: Geometry also?

Mu-Fa Chen: Yes. In middle school we had so much homework that we had to plan our time carefully in order to get everything done. Even now, I am surprised when I recall that period; not only middle school, but also other periods, for example when I was in the Guizhou province for six years.

I wrote two Masters theses, learned from Loéve's book, went to more than fifty factories, taught middle school, translated two books, and wrote several articles. All in six years.

Khoshnevisan/Waymire: You taught yourself how to read Loéve's book?

Mu-Fa Chen: Yes. My teacher suggested that I read Loéve's book because I did not know much probability. My teacher was a probabilist, so he suggested to me to first read half of the first volume by William Feller, Introduction to Probability Theory. That was in my sophomore year, and my teacher was my advisor. I spent three months reading this and when I went to the Guizhou province I found out that I needed more training. So I wrote to my teacher to ask for his help.

It was a strange situation, and you may not be able to understand it. After a few months, the Cultural Revolution 


\section{That's the} reason I can keep doing mathematics, because the people need it.

happened. We had little freedom, and I could not talk with my teacher for several years.

Khoshnevisan/Waymire: What age were you at this time?

Mu-Fa Chen: Nineteen, I think. We went to work at a factory and slept in the same room, forty people at a time. My teacher was there sleeping by me. Even then we could not talk. We had no such freedom.

Khoshnevisan/Waymire: You mean that you could not talk about mathematics?

Mu-Fa Chen: We could not talk about anything except in special cases. For example, when there was nobody around us, we could say hello to each other. When I moved to the Guizhou province I wanted to further my studies. So I wrote a letter to my advisor, asking for advice. My advisor went to the old bookshops and bought about fifteen books for me, maybe for about two dollars. Many scientists could not work at that time. Therefore, they sold their books to the bookstores. Everything was very cheap. One of those books was the third edition of Loéve's book. I spent two and a half years reading that book.

Khoshnevisan/Waymire: Do you know S. S. Chern from Berkeley?

Mu-Fa Chen: Yes. One day S. S. Chern suggested that I go to Berkeley to study with Jack Kiefer. Kiefer is one of the founders of optimization. I had written four papers on that topic. So Chern suggested to me to study optimization with Kiefer. But, during that period, I was on my way to probability theory, and could not change.

Khoshnevisan/Waymire: Was your interest in optimization related to your work in the factories?

Mu-Fa Chen: Yes. Two months before I left Beijing for Guizhou, I attended a talk by K. Hua, a top mathematician in China. K. Hua went to a factory and talked about optimization to the workers there. One of my classmates asked me to attend this talk. I attended that talk but it surprised me so much. Hua gave a large number of examples of how mathematics improved the working conditions, the working results, and so on. So when I went to the Guizhou province, maybe the next day, I tried to find out which factories were interested in this approach. The workers asked me to teach them mathematics because I was a teacher. They would drive to my home, because I walked, and bring me to their homes; a very lovely story in that period. That's the reason I can keep doing mathematics, because the people need it.

Khoshnevisan/Waymire: So what was the next phase of your life after this?

Mu-Fa Chen: After I finished my study of Loéve's book, I was lucky to find a new paper by Zhen-Ting Hou, a probabilist from the Hunan province, not far from Guizhou. In 1974, Hou published a uniqueness criterion for $Q$-processes of time-continuous Markov chains in the nonconservative case. The problem in the conservative case was solved by G. E. H. Reuter in 1957. In 1975 I contacted Hou, and then I started to study Markov chains. One year later I got a chance to visit him. I spent two months in Changsha. Every day we studied Kai-Lai Chung's book Markov Chains with Stationary Transition Probabilities, but not inside a room. We went out on a hill, you see. So every day we studied Chung's book out on a hill in secret, because there was not much freedom. Then I translated about half of Chung's book into Chinese.

Khoshnevisan/Waymire: Was Chung visiting China in that period?

Mu-Fa Chen: His visit was around 1977. After the Cultural Revolution people were looking for new research directions. Chung introduced us to a new direction by Dobrushin's group, called Random Fields. I returned to Beijing in 1978 and started our study of Random Fields for nearly one semester. Then we saw several articles by Tom Liggett, and we learned of Spitzer's ideas on interacting particle systems. Particle systems were more close to

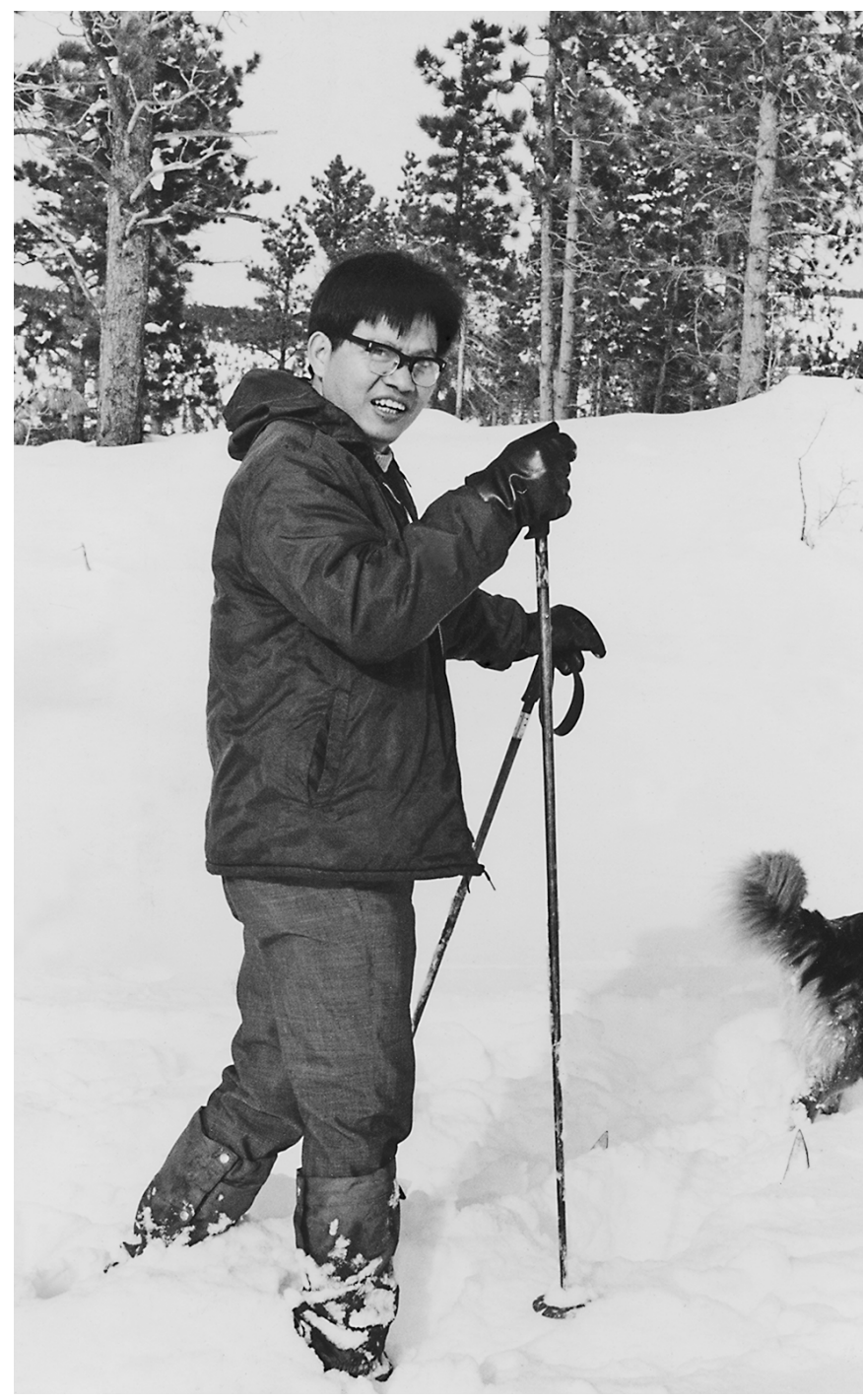

Chen in the Rocky Mountains, Boulder, Colorado, 1982. 
us because we were working on time-continuous Markov chains. That was the beginning step. From that time on I finally had the working environment that I needed to fully devote myself to mathematical research.

Khoshnevisan/Waymire: Did people from Frank Spitzer's group visit you in China?

Mu-Fa Chen: Yes. Spitzer visited me for forty-five days in 1984, though he was not well at that time. Maybe we asked him to lecture too much. To this Spitzer would joke and say, "I have now become a lecturing machine!"

Khoshnevisan/Waymire: Did you know R. L. Dobrushin's group as well?

Mu-Fa Chen: Certainly. Dobrushin visited us for forty-five days in 1988. I also visited him, and his group, and I now have a lot of Russian books.

Khoshnevisan/Waymire: Do you read Russian also?

Mu-Fa Chen: Yes, but not so much now. I recall that there was very heavy snow in the winter when I visited Moscow. Dobrushin spent half a day with me going to shops to buy a lot of books. Finally, he took me to a restaurant where he was very proud to say that it was the first private restaurant in Moscow. We even had a joint research project and the members of the groups visited each other for some years afterwards to work on the project.

Khoshnevisan/Waymire: Was your first visit to Dobrushin in the 1970s?

Mu-Fa Chen: Actually, it was several years later, at the end of 1988. I returned to the university only in 1978 .

Khoshnevisan/Waymire: You mentioned G. E. H. Reuter. Did you meet him as well?

Mu-Fa Chen: Yes, I met Reuter at the International Conference on Probability Theory in Cambridge in April 1987. Reuter had made great contributions to the theory of Markov chains. I asked him, and also David Kendall, how to do research. I asked everybody questions, because, you see, I had to teach myself. So whenever I met someone I asked for advice. When I asked how to do research Reuter answered that his supervisor Littlewood told him not to read anything before doing research. I often feel that I have not listened to him enough, but I have remembered his advice.

Khoshnevisan/Waymire: It seems to us that you absorbed many of those influences, and then added to them in your work. Even in your lecture today, we saw that. From optimization all the way through Markov chains to quantum field theory, interacting particle systems, and random fields.

Mu-Fa Chen: Yes. That is because I was not well educated by the university system. Somehow I had more freedom to go from here to there to ask questions.

Khoshnevisan/Waymire: In your own mathematical work, is there something special that you feel happiest about?

Mu-Fa Chen: Yes. I will give you two examples. The first example is our study of infinite-dimensional mathematics. We started from local, finite-dimensional mathematics.
We had many models from nonequilibrium statistical mechanics in mind, at least sixteen models. First, we had to prove the uniqueness of local processes; physicists are not interested in this [Laughs]. Then, the question was to prove uniqueness for high-dimensional Markov chains. The only known theory was based on solving a homogeneous equation. The process is unique when the equation has only the trivial [zero] bounded solution. In high dimensions, this equation consists of infinitely many variables. I had no idea how to solve such an equation. So I spent five years on this problem. In the end I found a beautiful sufficient condition which covers all the examples or models that I had in mind. I also proved that the condition is necessary in all computable cases. I didn't know about the more general case. That was in 1983, when I returned from the United States to China. Surprisingly, a few months ago, a researcher from the Netherlands proved that my sufficient condition is also necessary for a large class of Markov chains. That's the first example.

The second example comes from my study of the first nontrivial eigenvalue. I published the first paper in 1991. At the time, one could compute precisely the principal eigenvalue of the generator of a Markov chain in only two or three examples. If you take a look at this paper and compare it with what I talked about today, you will see how far we have come since then. The four volumes of the collections of papers in my homepage ${ }^{2}$ record the long journey that we have traveled in the past twenty-five years.

Also, regarding the geometric case, some time ago I might have given a talk here on Riemannian geometry. With my former student, Feng-Yu Wang, we found a new variational formula for the first nontrivial eigenvalue of Laplacian on a Riemannian manifold. This is exciting because people have worked on such problems for many years, and our formula includes most of the previously-known results.

Khoshnevisan/Waymire: How did you get interested in that particular problem? Were you reading S.T. Yau's work?

Mu-Fa Chen: Yes. At the beginning, I wanted to describe phase transition using the first nontrivial eigenvalue. I learned this idea from Tom Liggett, and also from Richard Holley and Daniel Stroock.

Khoshnevisan/Waymire: Did Holley and Stroock also come to China?

Mu-Fa Chen: Yes. Stroock was my supervisor when I visited the States. From him, I learned Malliavin calculus, large deviations, and many other things. He has visited China many times. I also arranged the visits of Tom Liggett, Rick Durrett, and Frank Spitzer. During 1988-1989, in particular, there was a special year dedicated to probability and statistics at Nankai University at S. S. Chern's Institute. At that time, Holley and Stroock were in China. We benefitted a great deal from the interactions with American probabilists.

math0.bnu.edu.cn/ chenmf 


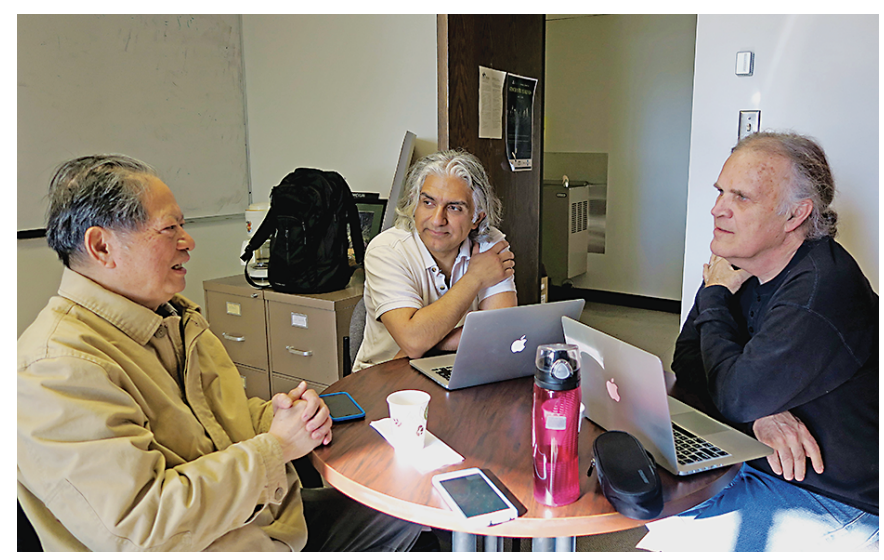

Chen being interviewed by Khoshnevisan and Waymire at the Frontier Probability Days Conference, Salt Lake City, 2016.

Khoshnevisan/Waymire: In particular, at that time, did you know geometry? Did you have to learn geometry?

Mu-Fa Chen: Geometry was popular in China because of S. S. Chern. So I did learn the fundamental points of the theory. One geometer came to my university to give a short course. I attended his course; that was the first time I learned some geometry. The second time was when I visited Daniel Stroock here. He also gave some lectures on geometry. All this happened in the early 1980s. After that, I studied geometry selectively.

I learned from the third chapter of a book by S. T. Yau on Riemannian geometry. That chapter concentrated on the first eigenvalue and I wanted to borrow tools from it. Somehow, for reasons of luck, we went the opposite direction, using coupling techniques to recover all of these results. I kept thinking that there was something left to improve upon, some places to go further. But we didn't know where to go. This was a challenging problem until one day I realized that we could find a good way to mimic the eigenfunction. This turned out to be important. That was my initial contribution to the eigenvalue problem until today. After we found out how to mimic the eigenfunction, the story was complete. Since I could not solve this problem for a long time, I got very tired, and sometimes was tempted to publish just what I had. But I ignored it and went to smoke a cigarette instead. I was a smoker at that time. It calmed me when I smoked. Unexpectedly, one day after having a smoke, suddenly a new idea came. Be careful, this by no means encourages smoking! In fact, I quit smoking years ago [Laughs]. During that time, my student F. Y. Wang was in the UK. When he came back, I told him the idea in ten minutes or so. Sometimes people say that it is the coupling and the distance method; we needed to understand how to choose the distance. In other words, we needed to understand how to mimic the eigenfunction and that is the key point.

Khoshnevisan/Waymire: I have heard that you have also translated a lot of mathematics into Chinese.

Mu-Fa Chen: Yes. But we did not publish much of that. We just mimeographed those notes and distributed them to our colleagues. I still have some copies.
Khoshnevisan/Waymire: Was that a lot of work?

Mu-Fa Chen: Certainly. This was from 1972 to 1976. In the next few years, around 1978, even in the early 1980s, we still often copied papers by hand. The copy machine was not popular until maybe the end of the 1980s.

Khoshnevisan/Waymire: You seem to have a good facility for language. Did you have that from childhood?

Mu-Fa Chen: Yes. In middle school and the first two years of university I only learned Russian. The foreign language of the whole country was Russian at that time. At a teacher's suggestion, I started to learn English. I had asked my teacher whether it was okay for me to do research in mathematics without learning English, and he said no without hesitation [Laughs]. So I had to learn English by myself, privately. At first I borrowed an English mathematics book. I checked every word using a dictionary, letter by letter. Since I didn't know how to pronounce the words, I simply memorized the letters in each word. After I learned two to three hundred words it became too difficult to continue in this way. So I asked the same teacher whether I could learn English without having to speak it. He immediately replied, "No, that is impossible." [Laughs], I could not remember what I had learned. So I borrowed a self-learning English book. That book taught me to speak English with the help of Chinese spelling. So every day I learned English using Chinese spelling. After many years, when I taught at a middle school, every day I read Loéve's book in English.

An English teacher at the school was surprised because no one else was learning science in English. She asked me to read a paragraph to her. After I read a paragraph, she said that she did not understand any of my words [Laughs]. After some years, I entered the university as a graduate student, and studied English regularly as a foreign language. In the first class, since the teacher had seen my homework...I told you that I was good at writing...the teacher thought that maybe my English was very good. So the teacher asked me a question. The question was, "What's your name?" I could not understand that question [Laughs]. It is very different after gaining some experience. For example, I spent fifteen months in the States. I also spent one year in the UK. My language improved a lot after that but still it is very limited.

Khoshnevisan/Waymire: Where in the States were you?

Mu-Fa Chen: Colorado. I suppose that I have not traveled enough in the States. And this is my third visit to Utah, so thank you very much.

Khoshnevisan/Waymire: We should thank you. We certainly hope that you will visit us many more times.

Mu-Fa Chen: Thank you so much.

Photo Credits

All photos courtesy of Mu-Fa Chen. 